\title{
Can Vitamin E be a Key Supplementation in Polycystic Ovary Syndrome
}

\author{
Atheena Mukundan $\mathbf{V}^{1, *}$, S. Jayakumari ${ }^{2}$ \\ 1Department of Pharmacy Practice, VISTAS, Chennai, Tamil Nadu, INDIA. \\ 2Department of Pharmacognosy, VISTAS, Chennai, Tamil Nadu, INDIA.
}

\begin{abstract}
Background: Vitamin E is not a hormone but acts like a hormone (Progesterone). As well as reduce the negative effects of too much androgens. It can also improve insulin sensitivity and inflammation, so remain the most effective treatment strategy for PCOS subjects. This case study describes the effect of Vitamin E supplementation (400 IU/day) on Acne, Hirsutism, menstrual cycle and hormonal levels in a women with PCOS. Materials and Methods: It was a interventional study using Vitamin E Supplementation. Results: Fasting blood samples and BMI were checked before and after 12 weeks of intervention. An eminent relief in acne, hirsutism, menstrual cycle and hormonal levels like follows BMI $\left(28.9 \mathrm{~kg} / \mathrm{m}^{2} \mathrm{Vs} 27.6 \mathrm{~kg} / \mathrm{m}^{2}\right)$, FBS $(100 \mathrm{mg} / \mathrm{dl} \mathrm{Vs} 92 \mathrm{mg} / \mathrm{dl}),(4.97 \mathrm{IU} / \mathrm{L} \mathrm{Vs}$ 7.2IU/L), LH (18.03 IU/L Vs $15.21 \mathrm{IU} / \mathrm{L})$, total serum testosterone (130 ng/dl Vs $50 \mathrm{ng} / \mathrm{dl})$. Conclusion: Vitamin E can act as the key supplementation to be add on to the current treatment guideline in improving parameters of PCOS, which will further improve the quality of life in PCOS and also reduce the overall treatment cost, which are generally unaffordable by most individuals with PCOS in India.
\end{abstract}

Key words: Vitamin E, Polycystic ovary syndrome, LH, FSH, BMI.

Key messages: Vitamin E can act as the key supplementation to be add on to the current treatment guideline in improving parameters of PCOS, which will further improve the quality of life in PCOS and also reduce the overall treatment cost, which are generally unaffordable by most individuals with pcos in India.

\section{INTRODUCTION}

Polycystic Ovary Syndrome (PCOS) is of clinical and public health importance as it is very common, affecting up to one in five women of reproductive age. It has significant and diverse clinical implications including reproductive (infertility, hyperandrogenism, hirsutism), metabolic (insulin resistance, impaired glucose tolerance, type 2 diabetes mellitus, adverse cardiovascular risk profiles) and psychological features (increased anxiety, depression and worsened quality of life). ${ }^{1}$

Recent studies reveals that vitamin $\mathrm{E}$ possesses anti-oxidative, anti-inflammatory, anti-obesity, anti-hyperglycaemic, antihypertensive and anti-hypercholesterolemia properties. ${ }^{2}$ Vitamin $\mathrm{E}$ is not a hormone, but it acts like a hormone. Specifically Progesterone. It works to mimic the effects of progesterone in the body, as well as reduce the negative effects of too much androgens (oestrogen and testosterone), which mainly happens in PCOS. ${ }^{3}$

\section{CASE HISTORY}

A 22-year-old unmarried female patient came to department of obstetrics and gynaecology, in Employee State Insurance Corporation (ESIC) Hospital, Ayanavaram, Chennai, with chief complaints of irregular menses (a normal flow menses followed by period of amenorrhoea of 2 to 4 months) from past 1 year. She also had complaints of hair loss, acne and weight gain. She was not a known case of diabetes mellitus or Hyperthyroidisms and was treating with metformin $500 \mathrm{mg}$ twice daily. She was not received any hormonal treatment as was not willing for it. Vitamin E supplement (400 IU/day) was added to the current medication. And patient was advised to
DOI: 10.5530/ijopp.12.2.31

Address for correspondence: Dr. Atheena Mukundan.V, Department of Pharmacy Practice, VISTAS,Chennai-117, Tamil Nadu, INDIA.

Email Id: atheenavmukundan@ gmail.com

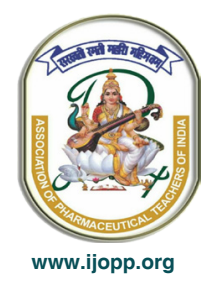


follow it for 12 weeks.

\section{On Examination}

Patient's vitals were good and family history was normal. From the personal history found that body weight began to increase gradually within past 2 years and in the past 10 months she gained around $6 \mathrm{~kg}$. Body weight and BMI were recorded before and after supplementation with vitamin $\mathrm{E}$.

\section{Laboratory Investigations}

Fasting Blood Sugar (FBS) (mg/dl), Follicular Stimulating Hormone (FSH) (IU/L), Luteinizing Hormone (LH) $(\mathrm{IU} / \mathrm{L})$ and Total serum testosterone (ng/dL) were measured before and after supplementation with Vitamin E.

\section{After 12 Weeks}

Patient was shown an eminent relief in acne, hirsutism, hormonal levels and patient also had regular menses on the past 2 months. (Table 1 ).

\begin{tabular}{|c|c|c|}
\hline PARAMETERS & BASE LINE & $\begin{array}{l}\text { AFTER } 12 \\
\text { WEEKS }\end{array}$ \\
\hline Body mass Index (BMI) & $28.9 \mathrm{Kg} / \mathrm{m}^{2}$ & $27.6 \mathrm{Kg} / \mathrm{m}^{2}$ \\
\hline Fasting blood sugar (FBS) & $100 \mathrm{mg} / \mathrm{dL}$ & $92 \mathrm{mg} / \mathrm{dL}$ \\
\hline $\begin{array}{l}\text { Follicular stimulating } \\
\text { hormone (FSH) }\end{array}$ & $4.97 \mathrm{IU} / \mathrm{L}$ & $7.2 \mathrm{IU} / \mathrm{L}$ \\
\hline Luteinizing hormone (LH) & $18.03 \mathrm{IU} / \mathrm{L}$ & $15.21 \mathrm{IU} / \mathrm{L}$ \\
\hline Total serum testosterone & $130 \mathrm{ng} / \mathrm{dl}$ & $50 \mathrm{ng} / \mathrm{dl}$ \\
\hline
\end{tabular}

\section{DISCUSSION}

Polycystic ovary syndrome is a common reproductive and cosmetic disorder of women in reproductive age. ${ }^{4}$ According to Endocrine Society released practice guidelines for PCOS, ${ }^{5}$ in adolescents with PCOS, hormonal contraceptives and metformin are the treatment options. ${ }^{6}$ Recent studies reveals that vitamin E possesses anti-oxidative, anti-inflammatory, antiobesity, anti-hyperglycaemic, anti-hypertensive and anti-hypercholesterolemia properties. ${ }^{2}$ Vitamin $\mathrm{E}$ is not a hormone, but it acts like a hormone. Specifically, Progesterone. It works by mimicking the effects of progesterone in the body, as well as by reducing the negative effects of high levels of androgens (estrogen and testosterone). ${ }^{3}$ In this case study after 12 weeks the total serum testosterone rate was decreased is an evident of this. In a study it was also found that, lifestyle modifications and the use of supplements including omega-3 and/or Vitamin E will improvement in insulin sensitivity and inflammation and remain the most effective treatment strategy for PCOS subjects. ${ }^{7,8}$

\section{CONCLUSION}

Vitamin E can act as the key supplementation to be add on to the current treatment guideline in improving parameters of PCOS, which will further improve the quality of life in pcos and also reduce the overall treatment cost, which are generally unaffordable by most individuals with pcos in India.

Further studies in large populations are needed to understand the efficacy and safety of vitamin E supplementation in polycystic ovary syndrome are required.

\section{ACKNOWLEDGEMENT}

We offer flowers of gratitude to my Almighty God, who has been the source of strength throughout our life. We are immensely thankful to Dr. P. Shanmugasundaram, Director, School of Pharmaceutical Science, VISTAS, Chennai, for his real motivation, encouragement and source of inspiration. We also thank all the respected Doctors and Nurses in the Gynaecology and Obstetrics, ESIC Hospital, Ayanavaram, Chennai, for providing us the excellent facilities and support for our work.

\section{CONFLICT OF INTEREST}

The authors declare no conflict of interest.

\section{ABBREVIATIONS}

PCOS: Polycystic ovary syndrome; BMI: Body Mass Index; FBS: Fasting Blood Sugar; LH: Luteinizing Hormone; FSH: Follicular Stimulating Hormone.

\section{SUMMARY}

An interventional case study was done with supplementation of Vitamin E (400 IU/day) to a women with polycystic ovary syndrome and it shown to have effect on various parameters such as BMI, FBS, LH, FSH and also on improving quality of life in her in a span on 12 weeks. So, Vitamin E can be a key supplementation to be add on in the current polycystic ovary syndrome treatment guidelines.

Indian Journal of Pharmacy Practice, Vol 12, Issue 2, Apr-Jun, 2019 


\section{REFERENCES}

1. Teede H, Deeks A, Moran L. Polycystic ovary syndrome: A complex condition with psychological, reproductive and metabolic manifestations that impacts on health across the lifespan. BMC Med. 2010;8(1):41.

2. Wong SK, Chin KY, Suhaimi FH, Ahmad F, Ima-Nirwana S. Vitamin E as a potential interventional treatment for metabolic syndrome: Evidence from animal and human studies. Front Pharmacol. 2017;8:444.

3. Cicek N, Erylimaz OG. Vitamin E effect on controlled ovarian stimulation of unexplained infertile woman. Journal of Assisted Reproduction and Genetics. 2012;29(4):325-8.

4. Kent SC, Gnatuk CL, Kunselman AR, et al. Hyperandrogenism and hyperinsulinism in children of women with polycystic ovary syndrome: A controlled study. J Clin Endocrinol Metab. 2008;93(5):1662-9.

5. Legro RS, Arslanian SA, Ehrmann DA, et al. Diagnosis and treatment of polycystic ovary syndrome: An Endocrine Society clinical practice guideline. J Clin Endocrinol Metab. 2013;98(12):4565-92. (ISSN: 1945-7197).
6. AlKhalifah RA, Florez ID, Dennis B, et al. Metformin or Oral Contraceptives for Adolescents with Polycystic Ovarian Syndrome: A Meta-analysis. Pediatrics. 2016;137(5):e20154089. (ISSN: 1098-4275).

7. Rahmani E, Samimi M, Ebrahimi FA, et al. The effects of omega-3 fatty acids and vitamin E co-supplementation on gene expression of lipoprotein(a) and oxidized low-density lipoprotein, lipid profiles and biomarkers of oxidative stress in patients with polycystic ovary syndrome. Mol Cell Endocrinol. 2017;439:24755.

8. Mehri J, Azadeh S, Mansooreh S, et al. The effects of omega-3 and vitamin E cosupplementation on parameters of mental health and gene expression related to insulin and inflammation in subjects with polycystic ovary syndrome. Journal of Affective Disorders. 2018;229:41-7. https://doi.org/10.1016/j.jad.2017.12.049. 